\title{
Prolonged dominance of follicles and reduced viability of bovine oocytes
}

\author{
I. Revah* and W. R. Butler \\ Department of Animal Science, Cornell University, Ithaca, NY 14853, USA
}

\begin{abstract}
Prolonging the lifespan of bovine follicles is known to result in reduced fertility after ovulation and insemination. In this study, the effect of prolonged development of follicles on oocyte viability was examined. In Expt 1 , six cows in the aspirated-prolonged-follicle group received a vaginal progesterone releasing device on day 4 of the oestrous cycle (day 1 = ovulation) and prostaglandin $F_{2 a}(40 \mathrm{mg})$ on day 6 . Ultrasound-guided follicular aspiration was performed on day 13 . Six cows in the aspirated-growing-follicle group received prostaglandin $\mathrm{F}_{2 \alpha}$ on day 6 , and follicular aspiration on day 7. In Expt 2, all cows were stimulated with $36 \mathrm{mg}$ FSH-P to develop multiple large follicles for study. Three cows in the prolonged-multiple-follicle group received the same treatment as did cows in Expt 1, but were ovariectomized on day 13. Three cows in the growing-multiple-follicle group received prostaglandin $F_{2 \alpha}$ on day 6 and were ovariectomized on day 7 . Oocytes recovered in both experiments were stained to reveal the stage of nuclear development. All oocytes from aspirated-prolonged and prolonged-multiple follicles showed expanded cumulus cells and condensed chromatin dispersed in the ooplasm, with possible germinal vesicle breakdown. Oocytes from aspirated-growing and growing-multiple follicles showed compact cumulus cells and an intact germinal vesicle. Plasma concentrations of oestradiol in both growing follicle groups increased until oocyte recovery. Oestradiol in the aspiratedprolonged-follicle group increased after luteolysis on day 6 and remained high until follicular aspiration. In contrast, in the FSH-stimulated prolonged-multiple-follicle group, oestradiol fell to trace amounts on day 8 and remained low. Oestradiol concentrations in follicular fluid were consistent with plasma concentrations for all groups. Bovine oocytes from prolonged dominant follicles undergo premature maturation in vivo, which perhaps accounts for the poor fertility observed in other studies when oestrous synchronization with progestins prolongs follicle lifespan.
\end{abstract}

\section{Introduction}

For decades, researchers have attempted to develop successful programmes to synchronize oestrus in cattle (for review see Jöchle, 1993). Progestins such as melengestrol acetate (MGA), controlled internal drug release-bovine device (CIDR-B), progesterone-releasing intravaginal device (PRID) and norgestomet implants (Syncro-Mate B) have been used to synchronize bovine oestrous cycles. Treatments used for more than 7 days result in good synchronization, but low fertility is observed at the first oestrus after progestin treatment (Hill et al., 1971; Henricks et al., 1973; Butcher and Pope, 1979; Macmillan et al., 1991; Jöchle, 1993; Savio et al., 1993a; Stock and Fortune, 1993; Wehrman et al., 1993). Several reports have noted that treatment with progestins induces prolonged development of the dominant follicle present at the time of treatment (Ulberg et al., 1951; Trimberger and Hansel, 1955; Zimbelman, 1963; Sirois and Fortune, 1990; Savio et al., 1993a).

*Requests for reprints

Received 5 July 1995.
When the progestin treatment is terminated, oestrus occurs followed by the LH surge and ovulation of the prolonged dominant follicle (Sirois and Fortune, 1990; Jöchle, 1993; Savio et al., 1993a; Stock and Fortune, 1993; I. Revah and W. R. Butler, unpublished). Since the corpora lutea that arise from persistent dominant follicles produce normal concentrations of progesterone, infertility cannot be attributed to luteal insufficiency (Stock and Fortune, 1993). However, infertility may be due to effects of prolonged follicular development on the oocyte or on the reproductive tract.

High oestradiol concentrations in plasma (Sirois and Fortune, 1990; Savio et al., 1993b; Custer et al., 1994) from cows with prolonged follicles, and higher LH pulse frequency (Roberson et al., 1989; Savio et al., 1993b; I. Revah and W. R. Butler, unpublished), result in an abnormal endocrine milieu in which the oocyte develops. It seems likely that protracted follicular development provoked by progestin treatment may compromise viability of oocytes leading to reduced fertility (Wise and Maurer, 1994; Wise et al., 1994). Maintaining follicles in prolonged dominance may cause premature maturation of the oocyte, i.e. the chromosomes condense and meiosis progresses 
to metaphase II, before the LH surge (Mihm et al., 1994). The objective of the present study was to compare the state of nuclear development of bovine oocytes obtained from normal and prolonged dominant follicles.

\section{Materials and Methods}

\section{Experiment 1}

Twelve lactating Holstein cows (3-4 years old) with regular oestrous cycles were used for ultrasound-guided follicular aspiration. Cows were housed at the Animal Science Teaching and Research Center at Cornell University. Animals were randomly assigned to two groups: aspirated-prolonged follicle (PF-ASP, $n=6$ ) and aspirated-growing follicle (GF-ASP, $n=6$ ). Cows were monitored twice a day for oestrus after prostaglandin $\mathrm{F}_{2 a}\left(\mathrm{PGF}_{2 u}\right)$-induced luteolysis $\left(\mathrm{PGF}_{2 u^{\prime}} 25 \mathrm{mg}\right.$ i.m., Lutalyse: Upjohn, Kalamazoo, MI). Cows in the PF-ASP group were fitted with a vaginal progesterone releasing device (CIDR-B, controlled internal drug release-bovine, Eazi-breed: Inter $\mathrm{Ag}$, Hamilton) on day 4 of the oestrous cycle (day $1=$ day of ovulation as determined by ultrasonographic examination), which remained in place for 9 days. On day 6 , cows in the PF-ASP and GF-ASP groups received PGF $_{2 \alpha}(25 \mathrm{mg}$ a.m. and $15 \mathrm{mg}$ p.m., i.m.). Oocytes were recovered by ultrasoundguided follicular aspiration, using the technique described by Presicce et al. (1995). An Aloka SSD-500V medical ultrasound unit (Corometrics Medical Systems, Inc., North Branford, CT) with a $5 \mathrm{MHz}$ convex array transducer was used to aspirate persistent dominant follicles from cows in the PF-ASP group on day 13 and growing dominant follicles from cows in the GF-ASP group on day 7 . The stainless steel needle guide on the probe was replaced with a 12-gauge $60 \mathrm{~cm}$ echogenic double lumen needle (Cook Veterinary Division, Spencer, IN), which was used to penetrate the vaginal wall and ovarian tissue for aspiration and flushing of the individual follicles. A vacuum pump was used for aspiration and the flow rate was adjusted to 20-30 ml min ${ }^{-1}$. Each follicle was flushed with $70-100 \mathrm{ml}$ sterile heparinized PBS. Most oocytes were found in the first $35 \mathrm{ml}$ flush, but some oocytes were found in the second or third flushes. Follicular fluid and flushing medium were aspirated into conical tubes and allowed to sediment. Tubes were transported at $35^{\circ} \mathrm{C}$ to the laboratory, where the media fractions were searched and oocytes were recovered. Follicular fluid was stored at $-20^{\circ} \mathrm{C}$ for steroid analysis.

\section{Experiment 2}

Large numbers of oocytes were obtained for evaluation by stimulating cows with FSH to produce multiple prolonged dominant and growing dominant follicles. Six non-lactating Holstein cows (3-4 years old) with regular oestrous cycles were randomly assigned to two groups: prolonged-multiplefollicle (PMF, $n=3$ ) and growing-multiple-follicle (GMF, $n=3$ ). Cows were monitored twice a day for oestrus after $\mathrm{PGF}_{2 \alpha}$-induced luteolysis (25 mg i.m.). Cows were stimulated with FSH using the following regimen: starting on day 1 (day of ovulation as determined by ultrasonographic examination), cows in the PMF and GMF groups received $3 \mathrm{mg}$ FSH (FSH-P:
Schering-Plough Animal Health Corp., Kenilworth, NJ) administered i.m. twice a day every $12 \mathrm{~h}$ until day 6 of the oestrous cycle (a total of $36 \mathrm{mg}$ FSH per cow; modified from Stock et al., 1993). On day 4, cows in the PMF group received a CIDR-B which remained in place intravaginally for 9 days. On day 6 , cows in the PMF and GMF groups received PGF $2 \alpha$ (25 mg a.m. and $15 \mathrm{mg}$ p.m., i.m.). Cows in the PMF group were ovariectomized on day 13, and cows in the GMF group were ovariectomized on day 7 of the cycle. Ovariectomy was performed by colpotomy, as described by Hofmeyer (1987). All cows were fasted for $12 \mathrm{~h}$ before surgery. Cows were prepared for surgery and were given an epidural block $(5 \mathrm{ml}$ $2 \%(w / v)$ injectable Lidocaine; The Butler Company, Columbus, $\mathrm{OH})$.

\section{Oocyte recovery}

After ovariectomy, ovaries were immediately transported to the laboratory (about $10 \mathrm{~min}$ ) in warm (approximately $35^{\circ} \mathrm{C}$ ) sterile saline solution. The cumulus-oocyte complexes and follicular fluid were first aspirated from preovulatory follicles (diameter range between 8 and $13 \mathrm{~mm}$ ) with an 18-gauge needle, and then each individual follicle was flushed with a comparable amount of PBS containing $10 \mathrm{iu}$ heparin $\mathrm{ml}^{-1}$ (heparin sodium 10000 USP (United States Pharmacopeia) units $\mathrm{ml}^{-1}$; Lyphomed, Deerfield, IL). The aspirated follicular fluid and flushing medium were transferred to separate conical centrifuge tubes, kept at $39^{\circ} \mathrm{C}$ and allowed to sediment for 10-15 min. After recovery of oocytes, follicular fluid was stored frozen for later analysis of oestradiol and progesterone.

\section{Monitoring follicular development}

In both Expts 1 and 2, ovaries were examined once a day starting on the day of oestrus (day 0 ) by ultrasonographic examination with a $7.5 \mathrm{MHz}$ intrarectal probe (Technicare 210DX, Corometrics, North Branford, CT) connected to a real-time B-mode linear array ultrasound scanner. Ovaries were scanned several times in at least two planes and examinations were recorded on videotape. The tapes were later reviewed to count the number and to measure the size of follicles throughout the treatment period. Only follicles $>8 \mathrm{~mm}$ were counted and measured.

\section{Blood sampling and endocrine analysis}

In both experiments, blood samples were collected daily from a coccygeal vessel to measure the concentrations of progesterone and oestradiol. Sampling started on day o (day of standing oestrus) and continued until ovariectomy or ultrasound-guided follicular aspiration. Samples were centrifuged immediately (1000 $\mathrm{g}$ for $20 \mathrm{~min}$ ) and plasma was stored frozen at $-20^{\circ} \mathrm{C}$ for later analysis. Progesterone (Elrod and Butler, 1993) and oestradiol concentrations (Schemm et al., 1990) in plasma and follicular fluid were measured by radioimmunoassay. Intra- and interassay coefficients of variation were $7.6 \%$ and $13.2 \%$ for progesterone $(n=3)$ and $8.5 \%$ and $14.6 \%$ for oestradiol $(n=4)$, respectively. All animal experimentation was performed in compliance with regulations set 
by the Center for Research Animal Resources, Institutional Animal Care and Use Committee (Cornell University, Ithaca, New York).

\section{Fixation and staining of oocyfes}

Oocytes were processed as described by Aman and Parks (1994). Briefly, oocytes were denuded of cumulus cells by vigorous vortexing in a microfuge tube $(1.5 \mathrm{ml})$ for $I \mathrm{~min}$ in PBS. Oocytes were fixed in $5 \%(\mathrm{w} / \mathrm{v})$ paraformaldehyde for at least $1 \mathrm{~h}$ and were stained with Hoechst 33342 stain (H-33342, $0.1 \mathrm{mg} \mathrm{ml}^{-1}$, Sigma, St Louis, MO) in PBS. Stained oocytes were mounted in Dulbecco's PBS:glycerol (1:1, w:W) under coverslips sealed with clear nail polish. A Zeiss microscope with phase contrast and epifluorescence capabilities at magnifications of $\times 100, \times 200$ and $\times 400$ was used to examine the nuclear chromatin of oocytes.

\section{Statistical analyses}

A $2 \times 2$ chi-squared contingency table was used to compare the stage of development of oocytes from cows in the PF-ASP and GF-ASP, or PMF and GMF treatment group. Analysis of variance with repeated measures was used to compare plasma concentrations of progesterone and oestradiol. Paired $t$ tests were used to measure the incremental change in progesterone and oestradiol from day 4 to day 5. Student's $f$ test was used to compare the final diameter of dominant follicles from treated and control cows for both Expts 1 and 2 and to compare oestradiol and progesterone concentrations in follicular fluid.

\section{Results}

\section{Experiment 1}

All oocytes (6 of 6) recovered from follicles from the GF-ASP group showed compact cumulus cells and an intact germinal vesicle (Fig. 1a). In contrast, all oocytes (6 of 6 ; $P<0.005$ ) recovered from follicles from the PF-ASP group (Fig. $\mathrm{Ib}, \mathrm{c})$ showed expanded cumulus cells and partially condensed or very condensed chromatin, which was often dispersed in the ooplasm, indicating a possible breakdown of the germinal vesicle. The final diameter of the dominant follicle before aspiration was significantly different between PF-ASP and GF-ASP cows $(21.4 \pm 1.6 \mathrm{~mm}$ and $15.2 \pm 0.8 \mathrm{~mm}$, respectively; $P=0.01$ ). Daily ultrasound examinations verified that the aspirated follicles had been present and developed from day 1 .

Plasma progesterone and oestradiol concentrations. As expected, plasma concentrations of progesterone increased in cows in the PF-ASP group from day 4 (insertion of CIDR-B) to day 5 (Fig. 2). Mean progesterone concentrations in plasma for GF-ASP cows increased until day 6, when luteolysis was induced (Fig. 2). In cows in the PF-ASP group progesterone concentrations also decreased after luteolysis and were maintained at $1.3 \pm 0.3 \mathrm{ng} \mathrm{ml}^{-1}$ (days 7-13 of the cycle) by the CIDR-B. Cows in the GF-ASP group showed a continuous increase in plasma oestradiol concentrations starting on day 3

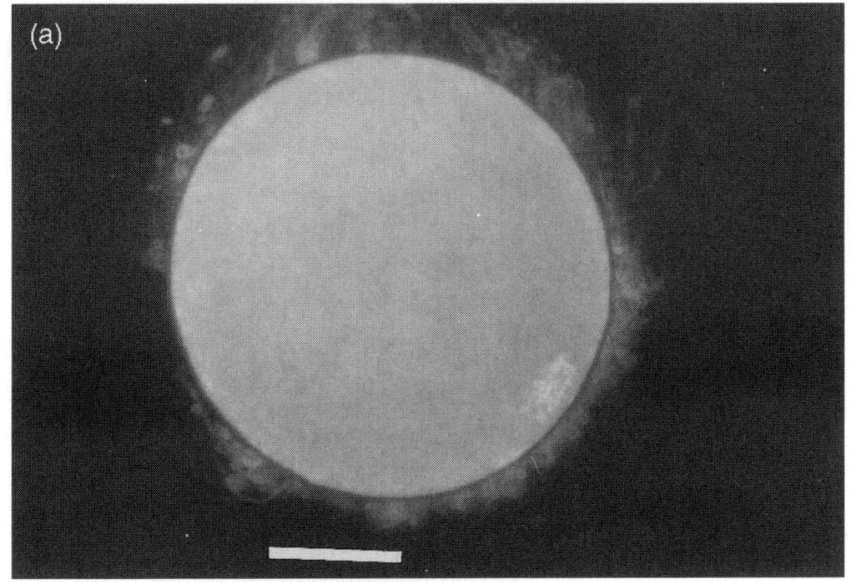

(b)

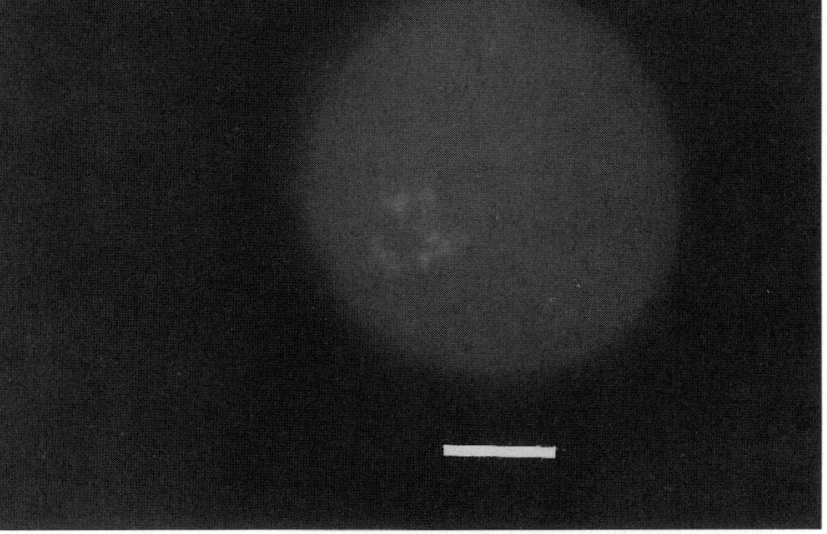

(c)

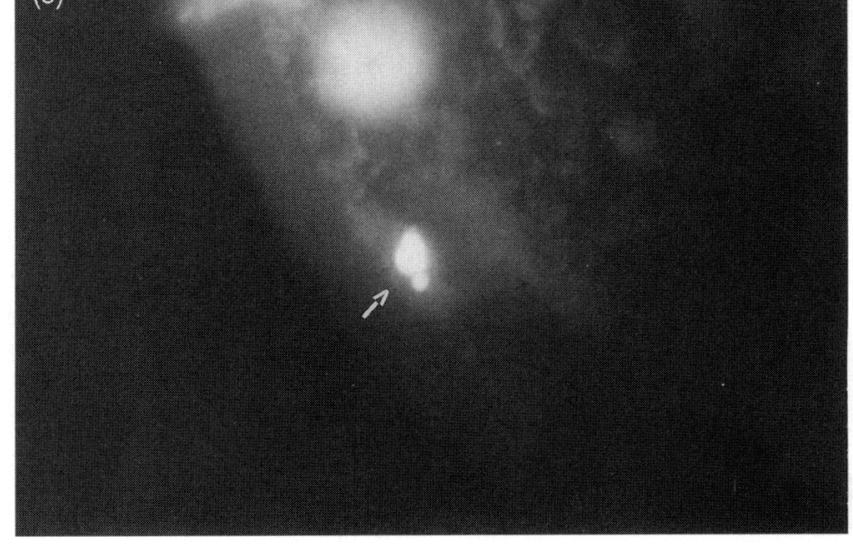

Fig. 1. Epifluorescent photomicrographs of bovine oocytes stained with Hoechst 33342 for DNA. (a) Oocyte with an intact germinal vesicle from a control cow from the GF-ASP group $(\times 82.5)$. (b) Oocyte with partially condensed chromatin with possible germinal vesicle breakdown from a cow in the PF-ASP group $(\times 82.5)$. (c) Oocyte showing an extruded polar body (arrow) bordering the zona pellucida on the focal plane of the oocyte from a cow in the PF-ASP group; note granulosa cells on the surface of the oocyte $(\times 165)$. Scale bars represent $30 \mu \mathrm{m}$.

(Fig. 3). Oestradiol concentrations in cows in the PF-ASP group (Fig. 3) remained low until lutcolysis was induced (day 6) and then increased until follicular aspiration (day 13). 


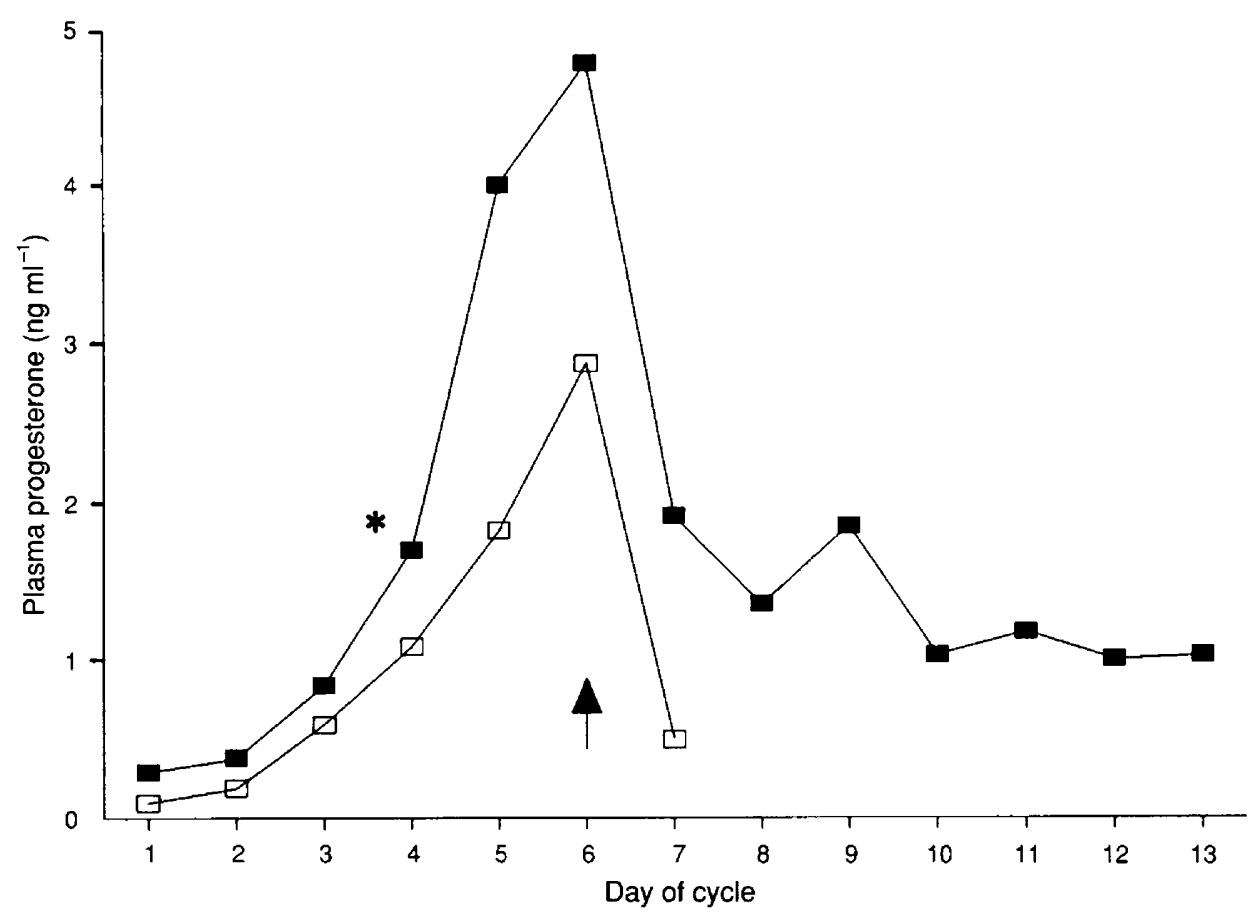

Fig. 2. Mean plasma concentrations of progesterone $\left(\mathrm{ng} \mathrm{ml}^{-1}\right)$ in Expt 1 . Cows with an aspirated prolonged follicle (PF-ASP group, $\square$ ) received a controlled internal drug release-bovine device on day $4\left(^{*}\right)$ and injections of $\mathrm{PGF}_{2 \alpha}$ on day 6 (arrow) of the oestrous cycle (follicular aspiration on day 13; $n=6$ ). Cows with an aspirated growing follicle (GF-ASP group, $\square$ ) received injections of PGF $_{2 u}$ on day 6 of the oestrous cycle (follicular aspiration on day $7 ; n=6$; SEM for progesterone $=0.15$ ).

Steroid concentrations in follicular fluid. Mean progesterone concentrations in follicular fluid were $71 \pm 10 \mathrm{ng} \mathrm{ml}^{-1}$ for cows in the PF-ASP group and $30 \pm 7 \mathrm{ng} \mathrm{ml}^{-1}$ for cows in the GF-ASP group $(P=0.05)$. Mean oestradiol concentrations in follicular fluid were $1.2 \pm 0.3 \mu \mathrm{g} \mathrm{ml}{ }^{-1}$ for PF-ASP and $1.3 \pm 0.3 \mu \mathrm{g} \mathrm{ml}^{-1}$ for GF-ASP cows $(P=0.84)$.

\section{Experiment 2}

Most oocytes $(24 / 29,83 \%)$ recovered from cows in the GMF group showed compact cumulus cells and an intact germinal vesicle (Fig. $4 \mathrm{a}, 5 \mathrm{~b}$ ). In contrast, all oocytes ( 23 of 23 , $100 \% ; P<0.005$ ) recovered from PMF cows showed expanded cumulus cells, partially condensed or very condensed chromatin, which was often dispersed in the ooplasm indicating a possible breakdown of the germinal vesicle (Fig. 4b, 5a, c). Ultrasonography verified the continuing development and persistence of follicles from day I until ovariectomy (day 13). The final diameter of dominant follicles before ovariectomy was greater for cows in the PMF group than for cows in the GMF group ( $11.4 \pm 0.1 \mathrm{~mm}$ and $9.15 \pm 0.1 \mathrm{~mm}$, respectively; $P=0.067)$.

Plasma progesterone and oestradiol concentrations. Plasma concentrations of progesterone increased in cows in the PMF group from day 4 (insertion of CIDR-B) to day 5 (Fig. 6), as observed in Expt 1. The incremental change in progesterone concentration was significantly different between PMF and GMF cows $(P=0.016)$. On day 6 , after $\mathrm{PGF}_{2 \alpha}$-induced luteolysis, the mean progesterone concentration declined in all cows, but was maintained at $1.6 \pm 0.3 \mathrm{ng} \mathrm{ml}^{-1}$ by the CIDR-B in cows in the PMF group.

In cows in the GMF group, plasma oestradiol concentrations increased from day 3 and remained high until day 7 (day of ovariectomy; Fig. 7). In cows in the PMF group, plasma concentrations of oestradiol decreased on day 5 (after CIDR-B insertion on day 4), but increased again on day 6 and 7, before falling and remaining at basal concentrations from day 8 until day 13 (day of ovariectomy; Fig. 7).

Steroid concentrations in follicular fluid. Mean progesterone concentrations in follicular fluid were $185 \pm 28 \mathrm{ng} \mathrm{ml}^{-1}$ and $30 \pm 12 \mathrm{ng} \mathrm{ml}^{-1}$ for cows in the PMF and GMF groups, respectively $(P=0.036)$. Mean oestradiol concentrations in follicular fluid were $5.3 \pm 0.2 \mathrm{ng} \mathrm{ml}^{-1}$ for cows in the PMF group and $233.7 \pm 4.4 \mathrm{ng} \mathrm{ml}^{-1}$ for cows in the GMF group $(P<0.005)$.

\section{Discussion}

The results of the study reported here confirm that oocytes recovered from follicles maintained under prolonged dominance undergo premature nuclear maturation in vivo. The results are in agreement with a preliminary report by Mihm et al. (1994). Results from other studies have shown that LH pulse frequency is increased (Roberson et al., 1989; Savio et al., 1993b; Stock and Fortune, 1993; Custer et al, 1994; I. Revah 


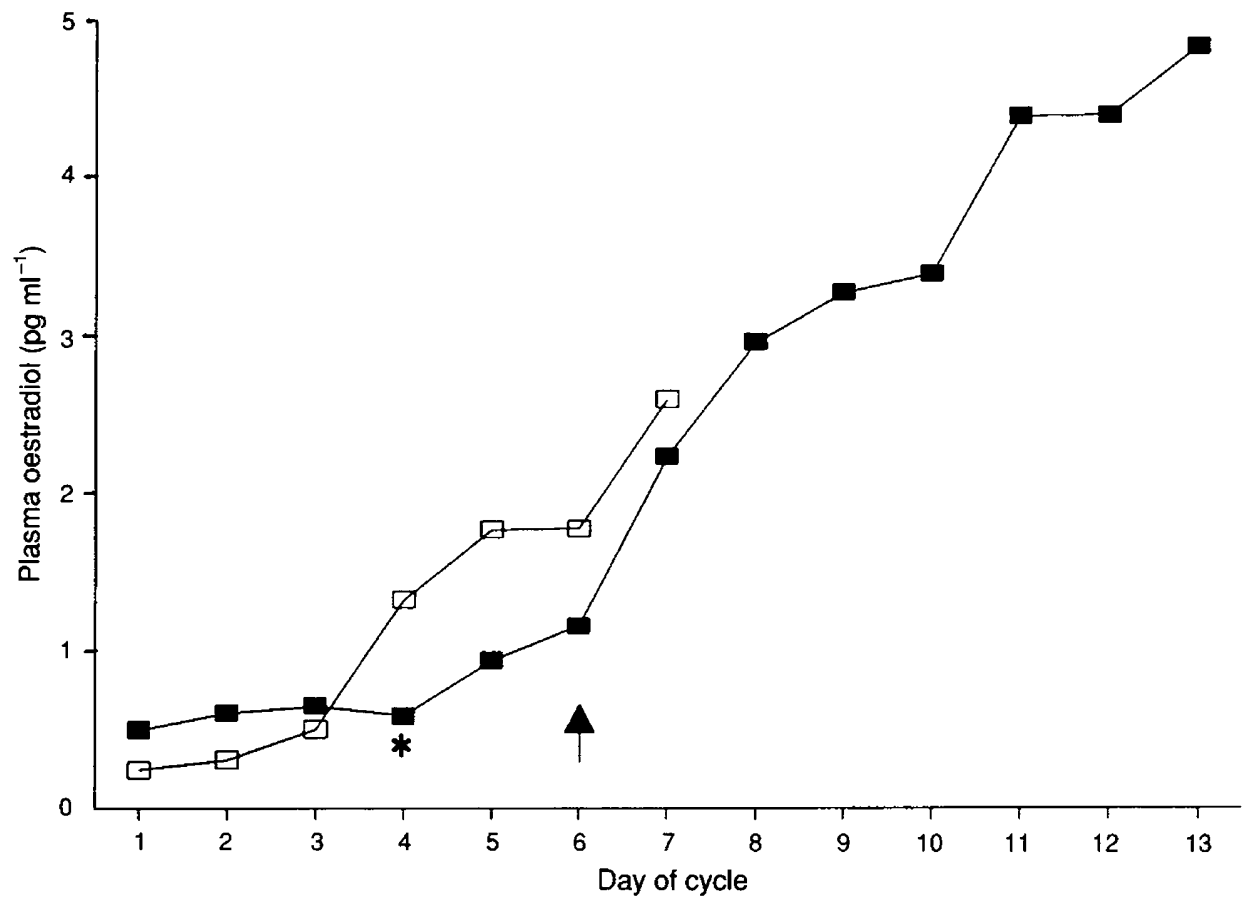

Fig. 3. Mean plasma concentrations of oestradiol $\left(\mathrm{pg} \mathrm{ml}^{-1}\right)$ in Expt 1 . Cows with an aspirated prolonged follicle (PF-ASP group, $\mathbf{\square}$ ) received a controlled internal drug release-bovine device on day $4\left(^{*}\right)$ and injections of $\mathrm{PGF}_{2 \alpha}$ on day 6 (arrow) of the oestrous cycle (follicular aspiration on day 13; $n=6$ ). Cows with an aspirated growing follicle (GF-ASP group, $\square$ ) received injections of PGF $_{2 u}$ on day 6 of the oestrous cycle (follicular aspiration on day 7; $n=6$; SEM for oestradiol $=0.21$ ).

and W. R. Butler, unpublished) and the LH surge is suppressed, when progesterone is maintained at lower concentrations to prolong follicular dominance (Savio et al., 1993a; Stock and Fortune, 1993; Vos et al., 1994). Mattheij et al. (1994) showed that an infusion of $\mathrm{LH}\left(14 \mathrm{ng} \mathrm{LH} \mathrm{min}^{-1}\right.$ for $50 \mathrm{~min}$ ) in rats can induce oocytes to undergo premature maturation without induction of ovulation. Bomsel-Helmreich et al. (1989) also showed that low doses of hCG ( 5 or $10 \mathrm{iu}$ ) were sufficient to induce resumption of meiosis, but were insufficient to induce ovulation in rabbits. The effects of injections of LH or hCG on oocytes suggest that prolonged exposure to increased LH pulse frequency may be sufficient to promote oocyte maturation in cows. Normally, oocyte maturation in vivo is induced by the preovulatory LH surge, but the maturation process must be mediated through granulosa cells, since oocytes lack receptors for LH (Eppig, 1991). One of the hypotheses to explain LH-induced maturation in rats is that LH induces degradation of gap junctions that couple mural granulosa cells to cumulus cells, resulting in a decreased flow of meiosis-arresting substances from granulosa cells to the oocyte (Wert and Larsen, 1990). It is possible that, in cattle, the increased LH pulse frequency resulting from low progesterone concentrations (I. Revah and W. R. Butler, unpublished) slowly affects the gap junctions between mural granulosa cells and cumulus cells. The deterioration of gap junctions may then allow the oocyte to resume meiosis, while still within the follicle.

The results of the present study indicate that maintaining follicles in prolonged dominance would have led to ovulation of a mature oocyte (i.e. an oocyte that had resumed meiosis), and that this would be expected to result in lower fertility after insemination. In rats, delaying ovulation of preovulatory follicles for 2 days resulted in decreased fertilization rates, decreased implantation rate, increased early embryonic death and increased incidence of chromosomal abnormalities owing to alterations of the preovulatory oocyte (Fugo and Butcher, 1966; Butcher and Fugo, 1967). Ahmad et al. (1995) reported that embryos obtained from cows that ovulated persistent follicles were compromised and could not reach the 16-cell stage.

Plasma concentrations of progesterone in cows in PMF and PF-ASP groups were maintained below mid-luteal concentrations $\left(<2 \mathrm{ng} \mathrm{ml}^{-1}\right)$ by the CIDR-B after induced luteolysis on day 6. Low plasma concentrations of progesterone resulted in prolonged growth and development of dominant follicles. Peripheral oestradiol concentrations were used to monitor functional development. Plasma oestradiol concentrations for cows in the GF-ASMP and GMF groups increased with follicular development until the day of oocyte recovery. In contrast to the rising oestradiol pattern in cows in the GF-ASP group, there was a suppressive effect of progesterone on oestradiol production in cows in the PF-ASP group; plasma oestradiol remained low $\left(<1 \mathrm{pg} \mathrm{ml}^{-1}\right)$ until after luteolysis on day 6 . The combined progesterone produced by the corpus luteum and the CIDR-B apparently inhibited oestradiol production by the developing dominant follicle until luteolysis occurred, after which follicular oestradiol production rapidly increased. In cows in the PMF group, similar inhibitory effect of progesterone was observed; plasma concentrations of oestradiol increased initially and then fell on day 5 in response to rising progesterone after CIDR-B insertion and in spite of 


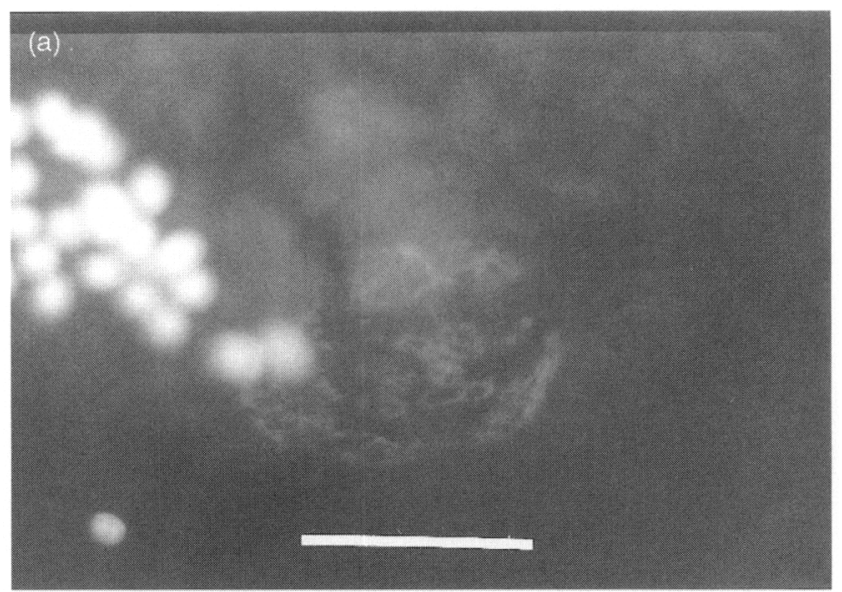

(b)

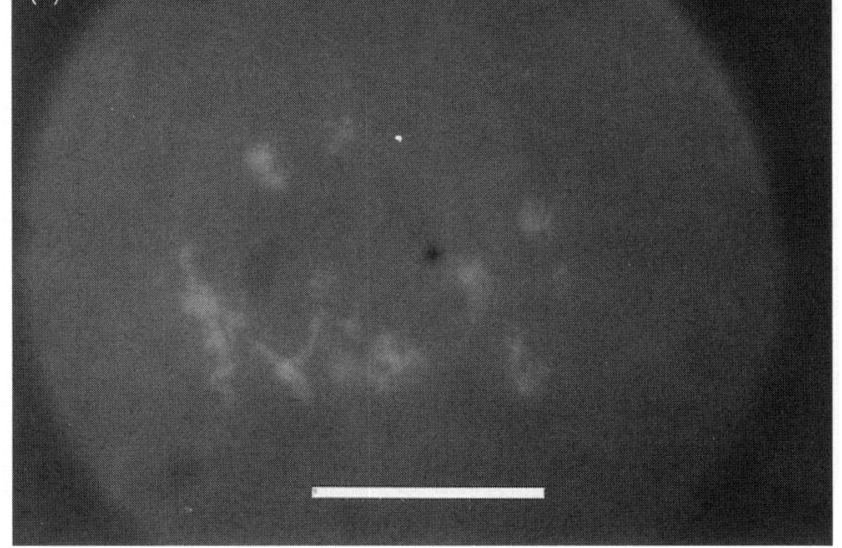

Fig. 4. Fpifluorescent photomicrographs of bovine oocytes stained with Hochst 33.342 for DNA la Oocyte with an intact germinal vesicle from an FSH-stimulated cow in the CMF group; note granulosa cells on the surface of the oocyte. (b) Oocyte with condensed and dispersed chromatin in the ooplasm and germinal vesick breakdown from an PSH-stimulated cow in the PMF group. Scale bars represent $30 \mu \mathrm{m}$.

continuing FSH stimulation. After luteolysis and lower progesterone concentrations oestradiol concentrations increased again until day 7 , but the recovery was short-lived and oestradiol concentrations declined to trace amounts until ovariectomy (day 13). A similar effect was reported by Hunter and Southee (1987), who found that ewes treated with progesterone produced large follicles with a significantly reduced capacity for oestradiol production owing to inhibition of aromatase.

Progesterone concentrations in follicular fluid confirm an earlier report by Wise of al. (1994), who found that follicular progesterone concentrations were increased in follicles with mature oocytes. Whether increased intrafollicular progesterone is a cause or effect related to early oocyte maturation remains to be determined. However, increased intrafollicular progesterone might be expected in this situation as a response to the prolonged exposure to LH pulse stimulation.

Oestradiol concentrations in follicular fluid were highest in follicles that were not stimulated by FSH (PF-ASP and GF-ASP) groups compared with FSH-stimulated follicles (PMF and GMF
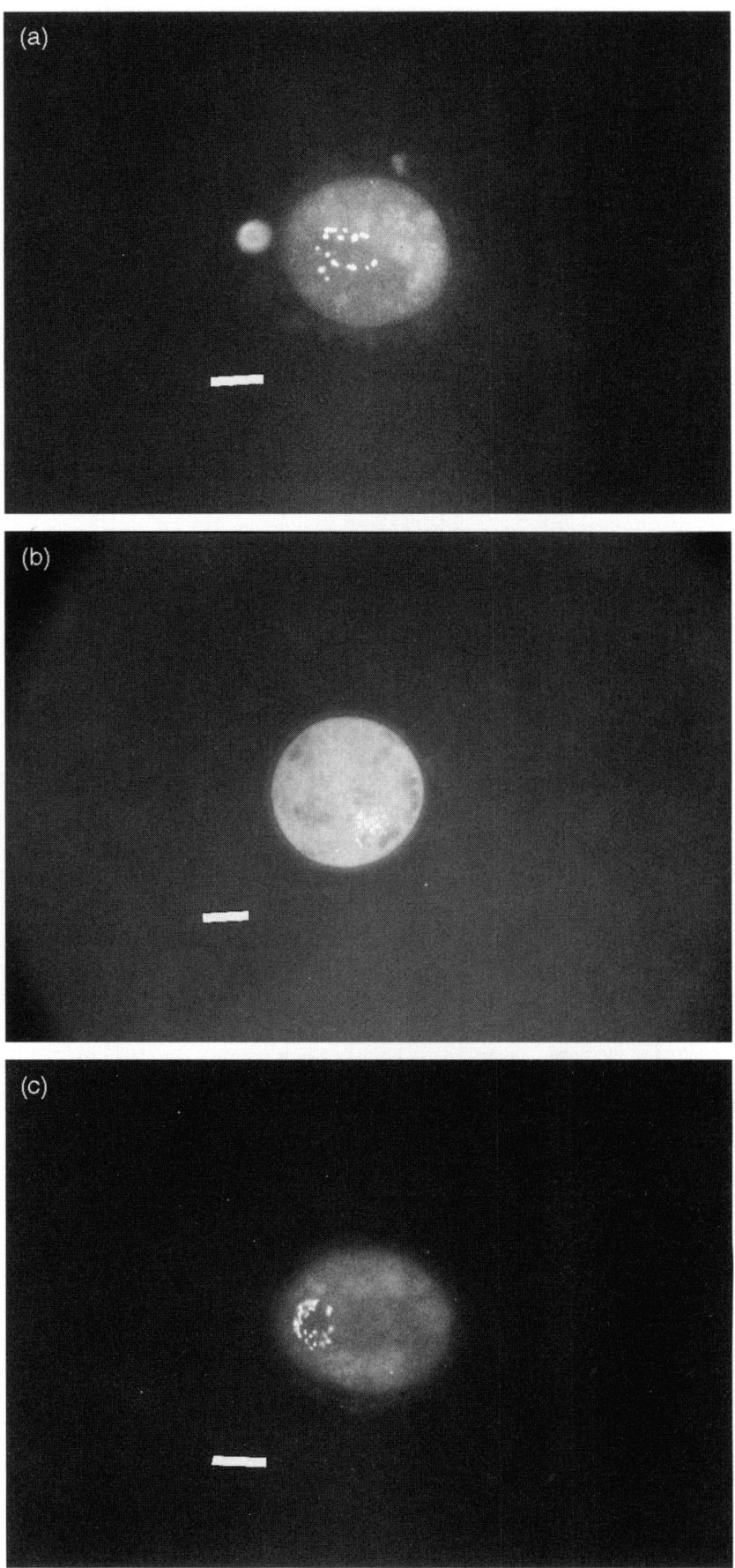

Fig. 5. Epifluorescent photomicrographs of bovine oocytes stained with Hoechst 3,3.12 for DNA. ai Oocyte with very condensed and dispersed chromatin and possible germinal vesicle breakdown from an FSH I-stimulated cow in the PMF group. (b) Oocyte with intact greminal vesicle from an FSH-stimulated cow in the GMF group. (c) Oocyte with very condensed and dispersed chromatin from an FSH I-stimulated cow in the PMF group. Scale bars represent $30 \mathrm{~km}$.

groups), which confirms previous reports (Fortune and Hansel, 1985; Assey et 11, 1994). These combined results indicate that, in response to exogenous gonadotrophin stimulation, the development of multiple large follicles is associated with reduced oestradiol synthesis. A related observation was that, 


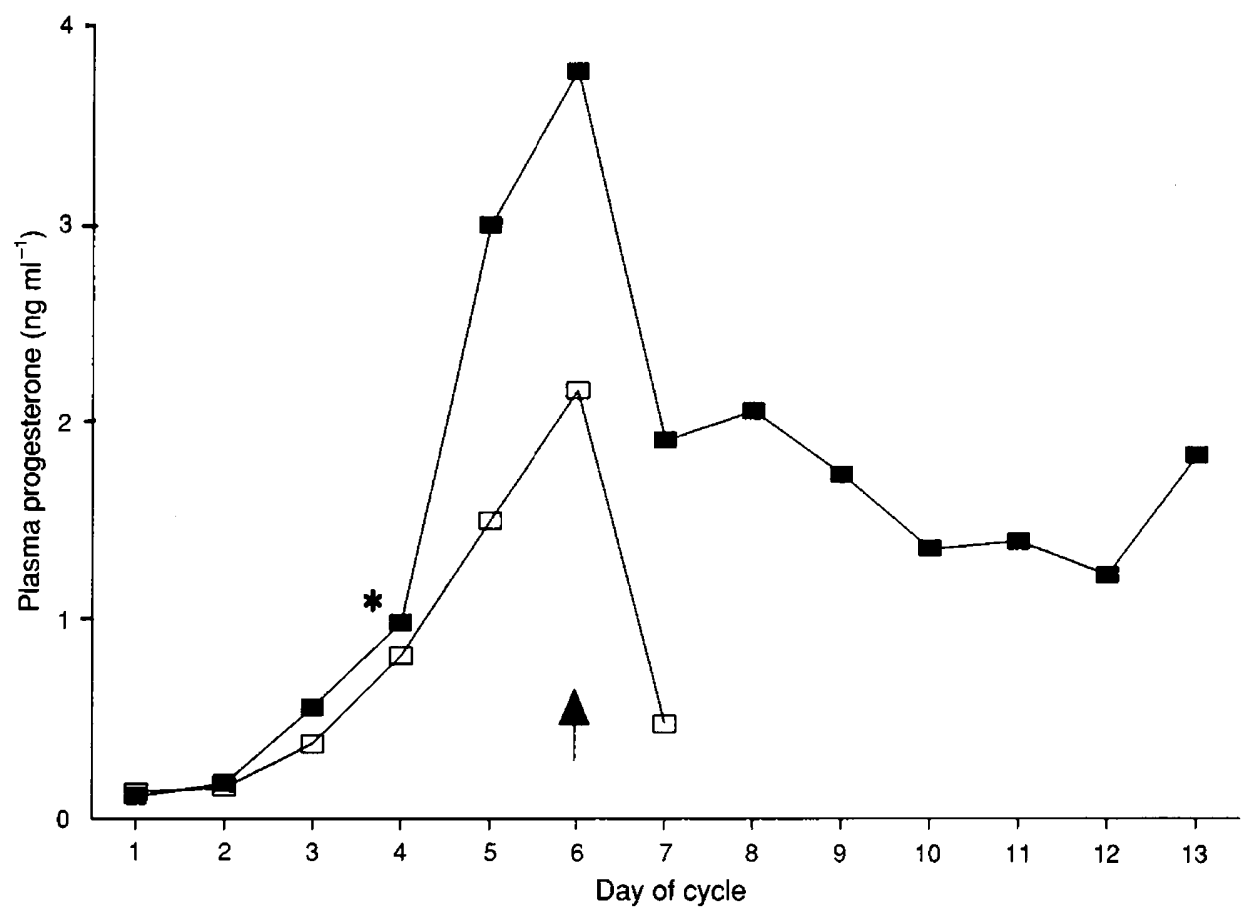

Fig. 6. Mean plasma concentrations of progesterone ( $\mathrm{ng} \mathrm{ml}^{-1}$ ) in Expt 2. Cows with prolonged follicles (PMF group, $\mathbf{D}$ ) received a controlled internal drug release-bovine device on day $4\left({ }^{*}\right)$ and injections of $\mathrm{PGF}_{2 \alpha}$ on day 6 (arrow) of the oestrous cycle (ovariectomy on day $13 ; n=3$ ). Cows with growing follicles (GMF group, $\square$ ) received injections of $\mathrm{PGF}_{2 \alpha}$ on day 6 of the oestrous cycle (ovariectomy on day 7; $n=3$; SEM for progesterone $=0.17$ ).

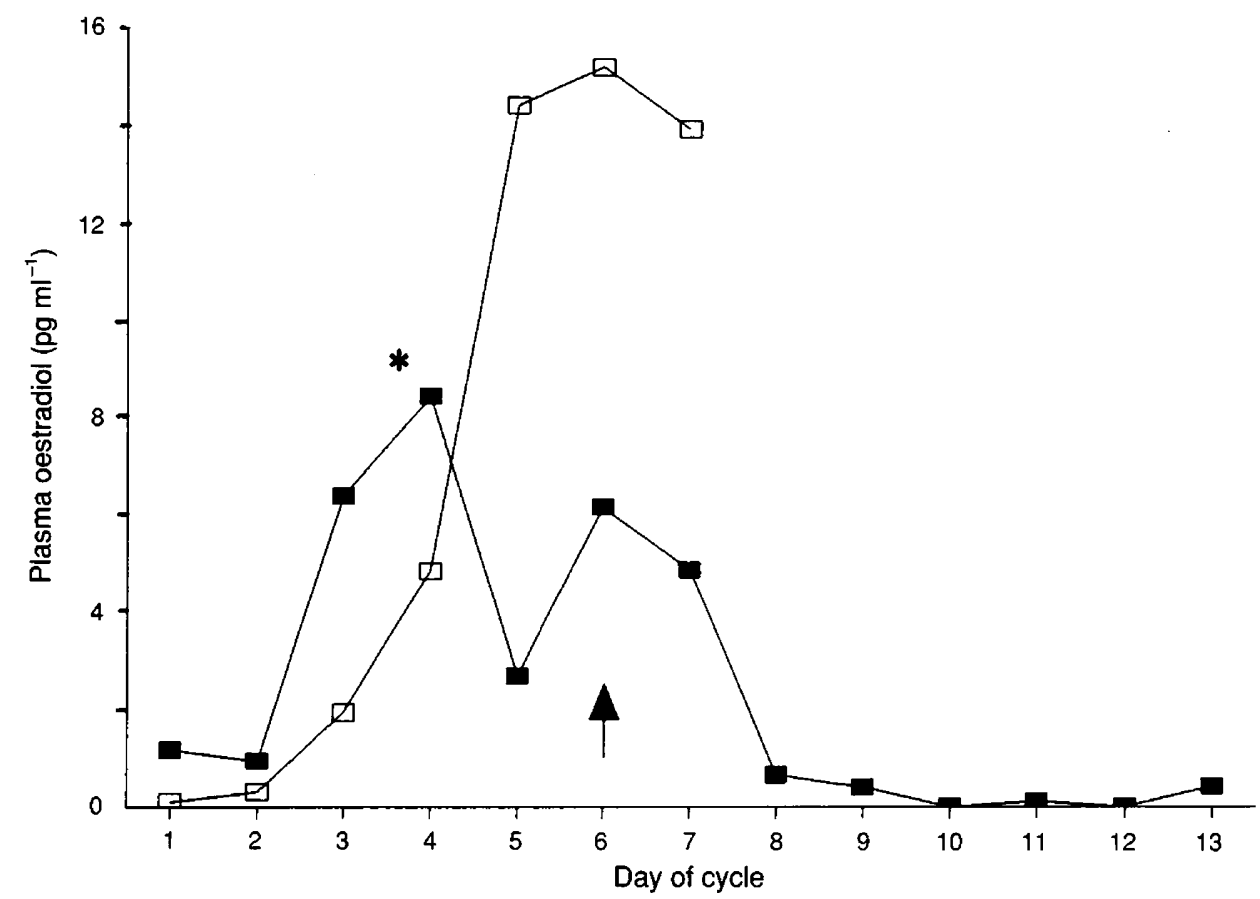

Fig. 7. Mean plasma concentrations of oestradiol ( $\mathrm{pg} \mathrm{m}^{-1}$ ) in Expt 2. Cows with prolonged follicles $(\mathrm{PMF}, \mathbf{\square})$ received a controlled internal drug release-bovine device on day $4\left(^{*}\right)$ and injections of $\mathrm{PGF}_{2 a}$ on day 6 (arrow) of the oestrous cycle (ovariectomy on day $13 ; n=3$ ). Cows with growing follicles (GMF group, $\square$ ) received injections of $\mathrm{PGF}_{2 u}$ on day 6 of the oestrous cycle (ovariectomy on day 7 ; $n=3$; SEM for oestradiol $=1.95$ ). 
by the day of ovariectomy, FSH-stimulated persistent follicles (PMF group) retained relatively little oestradiol synthetic capability based on follicular fluid oestradiol concentrations $\left(5.3 \mathrm{ng} \mathrm{ml}^{-1}\right)$. Plasma concentrations of oestradiol suggested that oestradiol production from follicles from the PMF group had diminished by day 8 . The apparent explanation is that the presence of the CIDR-B prolonged follicle persistence, but some aspect of oestradiol biosynthetic development had been compromised. Since FSH stimulation without CIDR-B yielded oocytes of normal appearance in the GMF group and the expected superovulatory response was obtained as in a previous study (Stock et al., 1993), FSH stimulation appears to provide the background for lower oestradiol production from multiple follicles, but this does not itself compromise oocyte viability. Furthermore, lack of oestradiol production in FSHstimulated large persistent follicles cannot be ascribed simply to their longevity, since concentrations of oestradiol in follicular fluid from individual persistent follicles (PF-ASP) was equivalent to that in single growing follicles (GF-ASP group). It is possible that lower oestradiol production during FSH stimulation results from inhibitory endocrine signalling among the cohort of multiple large follicles.

In summary, the results of the present study indicate that oocytes from prolonged dominant follicles have undergone premature maturation in vivo. This alteration of oocyte status in persistent follicies may be responsible for the poor fertility observed after oestrous synchronization in cattle administered progestin treatment for longer than 7 days. Prolonged dominance seems to be responsible for altering the microenvironment for normal development of the oocyte and, thereby reducing the chances of successful embryo development and pregnancy.

The authors thank S. W. Beam, R. S. Marcucio, G. A. Presicce and R. R. Saatman for their technical assistance with surgeries and oocyte manipulations, InterAg (Hamilton, New Zealand) for providing the CIDR-B devices used in this project, USDA Regional Research Project NE-161 for funds allocated to the project and the personnel at the Dairy Unit of the Animal Science Teaching and Research Center at Cornell Univesity, for animal care and blood sampling.

\section{References}

Ahmad N, Schrick FN, Butcher RL and Inskeep EK (1995) Effect of persistent follicles on early embryonic losses in beef cows Biology of Reproduction $\mathbf{5 2}$ $1129-1135$

Aman RR and Parks JE (1994) Effects of cooling and rewarming on the meiotic spindle and chromosomes of in vitro matured bovine oocytes Biology of Reproduction 50 103-110

Assey RJ, Hyttel P, Roche JF and Boland M (1994) Oocyte structure and follicular steroid concentrations in superovulated versus unstimulated heifers Molecular Reproduction and Development 39 8-16

Bomsel-Helmreich O, Vu N, Huyen L and Durand-Gasselin I (1989) Effects of varying doses of HCG on the evolution of preovulatory rabbit follicles and oocytes Human Reproduction 4 636-642

Butcher RL and Fugo NW (1967) Overripeness and the mammalian ova. II Delayed ovulation and chromosomal anomalies Fertility and Sterility 18 297-302

Butcher RL and Pope RS (1979) Role of estrogen during prolonged estrous cycles of the rat on subsequent embryonic death or development Biology of Reproduction 21 491-495
Custer EE, Beal WE, Wilson SJ, Meadows AW, Berardinelli JG and Adair R (1994) Effect of melengestrol acetate (MGA) or progesterone-releasing intravaginal device (PRID) on follicular development, concentrations of estradiol-17 $\beta$ and progesterone, and luteinizing hormone release during an artificially lengthened bovine estrous cycle Journal of Animal Science 72 1282-1289

Elrod CC and Butler WR (1993) Reduction of fertility and alteration of uterine $\mathrm{pH}$ in heifers fed excess ruminally degradable protein journal of Animal Science 71 694-701

Eppig J (1991) Intercommunication between mammalian oocytes and companion somatic cells BioEssays 13 569-574

Fortune JE and Hansel W (1985) Concentrations of steroids and gonadotropins in follicular fluid from normal heifers and heifers primed for superovulation Biology of Reproduction 32 1069-1079

Fugo NW and Butcher RL (1966) Overripeness and the mammalian ova. I. Overripeness and early embryonic development Fertility and Sterility 17 $804-814$

Henricks DM, Hill JR and Dickey JF (1973) Plasma ovarian hormone levels and fertility in beef heifers treated with melengestrol acetate (MGA) Journal of Animal Science 37 1169-1175

Hill JR, Lamond DR, Henricks DM, Dickey JF and Niswender GD (1971) The effect of melengestrol acetate (MGA) on ovarian function and fertilization in beef heifers Biology of Reproduction 4 16-22

Hofmeyer CFB (1987) Ruminant Urogenital Surgery p 124. Iowa State University Press, Ames

Hunter MG and Southee JA (1987) Treatment with progesterone affects follicular steroidogenesis in anoestrous ewes Animal Reproduction Science 14 $273-279$

Jöchle W (1993) Forty years of control of the oestrous cycle in ruminants: progress made, unresolved problems and the potential impact on sperm encapsulation technology Reproduction Fertility and Development 5 587-594

Macmillan KL, Taufa VK, Barnes DR and Day AM (1991) Plasma progesterone concentrations in heifers and cows treated with a new intravaginal device Animal Reproduction 26 25-40

Mattheij JAM, Swarts JJM, Hurks HMH and Mulder K (1994) Advancement of meiotic resumption in Graafian follicles by LH in relation to preovulatory ageing of rat oocytes Journal of Reproduction and Fertility 100 65-70

Mihm M, Curran N, Hyttel P, Boland MP and Roche JF (1994) Resumption of meiosis in cattle oocytes from preovulatory follicles with a short and a long duration of dominance Joumal of Reproduction and Fertility Abstract Series 13 Abstract 14

Presicce GA, Revah I, Yang X and Butler WR (1995) Ultrasound guided aspiration of large dominant or preovulatory follicles in cows: a new approach journal of Dairy Science $\mathbf{7 8}$ (Supplement I) Abstract 303

Roberson MS, Wolfe MW, Stumpf TT, Kittock RJ and Kinder JE (1989) Luteinizing hormone secretion and corpus luteum function in cows receiving two levels of progesterone Biology of Reproduction 41 997-1003

Savio JD, Thatcher WW, Morris GR, Entwistle K, Drost M and Mattiacci MR (1993a) Effects of induction of low plasma progesterone concentrations with a progesterone-releasing device on follicular turnover and fertility in cattle Joumal of Reproduction and Fertility 98 77-84

Savio JD, Thatcher WW, Badinga L, de la Sota RL and Wolfenson D (1993b) Regulation of dominant follicle turnover during the oestrous cycle in cows Journal of Reproduction and Ferfility 97 197-203

Schemm SR, Deaver DR, Griel LC and Muller LD (1990) Effects of recombinant bovine somatotropin on luteinizing hormone and ovarian function in lactating dairy cows Biology of Reproduction 42 815-821

Sirois J and Fortune JE (1990) Lengthening the bovine estrous cycle with low levels of exogenous progesterone: a model for studying ovarian follicular dominance Endocrinology 127 916-925

Stock AE and Fortune JE (1993) Ovarian follicular dominance in cattle: relationship between prolonged growth of the ovulatory follicle and endocrine parameters Endocrinology 132 1108-1114

Stock AE, Ellington JE and Fortune JE (1993) Follicular dominance in cattle: superovulatory responses in the presence versus absence of a dominant follicle Biology of Reproduction 48 (Supplement I) Abstract 189

Trimberger GW and Hansel W (1955) Conception rate and ovarian functions following estrus control by progesterone injections in dairy cattle Journal of Animal Science 14 224-232

Ulberg LC, Christian RE and Casida LE (1951) Ovarian response in heifers to progesterone injections Journal of Animal Science $10752-759$

Vos PLAM, Bevers MM, Willemse AH and Dieleman SJ (1994) Effects of suppression by a progesterone-releasing intravaginal device and subsequent 
induction by $\mathrm{GnRH}$ of the preovulatory $\mathrm{LH}$ surge on follicular function in PMSG/PG-treated heifers Journal of Reproduction and Fertility 101 43-49

Wehrman ME, Roberson MS, Cupp AS, Kojima FN, Stumpf TT, Werth LA, Wolfe MW, Kittok RJ and Kinder JE (1993) Increasing exogenous progesterone during synchronization of estrus decreases endogenous $17 \beta$-estradiol and increases conception in cows Biology of Reproduction 49 214-220

Wert SE and Larsen WJ (1990) Preendocytotic alterations in cumulus cell gap junction precede meiotic resumption in the rat cumulus-oocyte complex Tissue and Cell 22 827-852

Wise T and Maurer RR (1994) Follicular development, oocyte viability and recovery in relation to follicular steroids, prolactin and glycosaminoglycans throughout the estrous period in superovulated heifers with a normal LH surge, no detectable LH surge, and progestin inhibition of LH surge Domestic Animal Endocrinology 11 35-58

Wise T, Suss U, Stranzinger G, Wuthrich K and Maurer RR (1994) Cumulus and oocyte maturation and in vitro and in vivo fertilization of oocytes in relation to follicular steroids, prolactin and glycosaminoglycans throughout the estrous period in superovulated heifers with a normal LH surge, no detectable LH surge, and progestin inhibition of $\mathrm{LH}$ surge Domestic Animal Endocrinology 11 59-86

Zimbelman RG (196,3) Determination of the minimal effective dose of $6 \alpha$-methyl-17a-acetoxy-progesterone for control of the estrous cycle of cattle Journal of Animal Science 22 1051-1058 